\title{
Computed tomography-guided Tru-cut biopsy of lung mass, as an important diagnostic tool: Histopathological characteristics, age, sex distribution, and risk factors in Misurata Cancer Center, Libya
}

\begin{abstract}
Background: Lung biopsies may be classified according to the method of access or by the reason for biopsy. Tru-cut biopsy is a simple, relatively safe, rapid, and reliable technique for the diagnosis of lung mass lesions, particularly with the aid of computed tomography (CT) scan. This procedure is commonly used worldwide to detect different kinds of lung tumors, but its usefulness in Libya is not yet studied.

Objectives: The aim of this study was to assess the usefulness of Tru-cut biopsy as a diagnostic method in lung tumors and also to determine the incidence of lung cancer in various ages and sex groups and in relation to smoking data.

Patients and Methods: Retrospective study was done on 136 patients who underwent CT-guided Tru-cut biopsy from January 2012 to March 2015. The included patients have lung mass lesions suspected to be neoplastic according to chest radiograph and/or CT scan.

Results: We found biopsies and histopathology reports of 136 cases. The patients' age was from 20 to 85 years with the peak incidence in the sixth and seventh decades. The benign lesions were 18 (13.23\%), and malignant lesions were $118(86.76 \%)$ documented microscopically. The most common tumor was squamous cell carcinoma (25.17\%), followed by adenocarcinoma (23.02\%) and small cell lung carcinoma (17.26\%). Nonspecific inflammation was found in $8.63 \%$.

Conclusion: CT-guided Tru-cut biopsy is a simple, safe, and reliable procedure with high diagnostic accuracy for the diagnosis and subtyping of lung cancer. The definitive result of malignancy is a base for correct decision for the patient's treatment after careful clinical correlation with performance state, radiology findings, and complete serological investigations.
\end{abstract}

Keywords: Adenocarcinoma, lung biopsy, lung mass, small cell lung carcinoma, squamous cell carcinoma, Tru-cut biopsy

\section{INTRODUCTION}

Lung biopsies may be classified according to the method of access (percutaneous, bronchoscopic, and open biopsy) or by the reason for biopsy (sampling of diffuse lung disease or obtaining tissue from a mass when malignancy is suspected). ${ }^{[1]}$ Sometimes, percutaneous biopsy is also defined by the tissue type obtained (e.g., cytological or histological). Tru-cut biopsy is a simple procedure, relatively safe, rapid, reliable technique for the diagnosis of lung mass lesions, particularly with the aid of computed tomography (CT) scan. ${ }^{[2-8]}$ Core biopsy not only distinguishes between benign and malignant lesions but also helps in tumor typing of lung cancer, so initiation

\begin{tabular}{|l|c|}
\hline \multicolumn{2}{|c|}{ Access this article online } \\
\hline \multirow{2}{*}{$\begin{array}{l}\text { Website: } \\
\text { www.asjo.in }\end{array}$} & Quick Response Code \\
\hline DOI: & \\
10.4103/ASJO.ASJO_12_17 & \\
&
\end{tabular}

of specific therapy chemotherapy or surgery is possible without unnecessary delay.

\footnotetext{
Mohamed Alhashmi M. Sidoun, Yasin Topov ${ }^{1}$, Mohamed A. Elfageh, Noura A. Mansour ${ }^{1}$, Abdullah A. Jwaid, Alhadi M. Jahan ${ }^{2}$, Mussa A. Alragig

Departments of Surgical Oncology and ${ }^{1}$ Clinical Histopathology, Misurata Cancer Centre, Misurata, Libya, ${ }^{2}$ Department of Graduate and Postdoctoral Studies, Faculty of Health Sciences, University of Ottawa, Ottawa, Canada

Address for correspondence: Dr. Mohamed Alhashmi M. Sidoun, Department of Surgical Oncology, Misurata Cancer Center, Misurata, Libya.

E-mail: dr.sidoun.mohamed1982@gmail.com
}

This is an open access article distributed under the terms of the Creative Commons Attribution-NonCommercial-ShareAlike 3.0 License, which allows others to remix, tweak, and build upon the work non-commercially, as long as the author is credited and the new creations are licensed under the identical terms.

For reprints contact: reprints@medknow.com

How to cite this article: M. Sidoun MA, Topov Y, Elfageh MA, Mansour NA, Jwaid AA, Jahan AM, et al. Computed tomographyguided Tru-cut biopsy of lung mass, as an important diagnostic tool: Histopathological characteristics, age, sex distribution, and risk factors in Misurata Cancer Center, Libya. Asian J Oncol 2017;3:111-5. 
The special advantage of core biopsy includes detection of those tumor types such as small cell carcinoma, lymphomas more appropriately treated by chemotherapy rather than surgery. Numerous published works consider CT-guided Trucut biopsy as an accurate, and sensitive diagnostic procedure in thoracic malignancy. ${ }^{[9,10]}$ The technique is almost minimum painful nonoperative procedure. Negative result from this study may be considered if a solitary pulmonary nodule has a high clinical suspicion of malignancy for operable tumor; negative biopsy is of limited value in the management. CT scan-guided Tru-cut biopsy is a useful tool for evaluating neoplastic and inflammatory lung nodules. This study was undertaken to assess the use of the technique in our oncology center.

\section{PATIENTS AND METHODS}

This study was conducted in the Misurata Cancer Center (MCC) in the period from January 2012 to March 2015. Continuous cases have been examined over a 3-year period. A total of 136 patients were referred for further investigations from different departments (e.g., chest, medicine, and oncology). The included patients have lung mass lesions suspected to be neoplastic according to chest radiograph and/or CT scan. Based on the CT findings, the lesions' size ranged from 2 to 9 $\mathrm{cm}$ in diameter. Out of 136 patients, 74 had a right side lung lesions, while left side lung mass was reported in 59 cases, bilateral lung lesions was observed in 2 cases, and only one patient was reported with anterior mediastinal tumor.

Before starting the procedure, an informed consent from the patients and an approval from the MCC ethical committee were provided. After evaluating risks and benefits, a CT-guided core biopsy of lung mass lesions was performed by consultant surgeon or consultant physician as an outpatient department procedure. An experienced radiologist is also present during the procedure to assist the physicians. From each patient, a complete blood count, viral screen, and blood coagulation screen tests were done before starting the procedure. The patient's position was supine, prone, or lateral according to the location of the lesion. The skin surface was cleaned with povidone iodine, and then, Tru-cut biopsy needle was introduced through a small skin incision, approach localizing the exact position by CT scan after the measurement of the site and angle of the entry of the needle, route of the needle, and the distance between the skin and lesion on the CT scan monitor. Following placement of the needle, a CT scan slice was taken to ascertain whether the tip of the needle was within the mass. The biopsy was obtained by to-and-fro movement of the needle within the mass by three to four trials and the tissue was sent immediately to the histopathology department. Patients were kept for $2 \mathrm{~h}$ under observation. In our study, mild hemorrhage was reported in 12 cases, mild pneumothorax in 14 cases, and air embolism in 1 case.

After fixation in $10 \%$ formalin solution for minimum $2 \mathrm{~h}$, the tissue was processed and embedded in paraffin wax. Microscopic sections of 4 to $6 \mathrm{mkm}$ thickness were stained with Hematoxylin and Eosin ( $\mathrm{H}$ and $\mathrm{E})$, and when needed, immunochemistry cytokeratin 5 (CK 5), CK 7, CK 20, chromogranin, synaptophysin, and CD stains for lymphoma were used.

\section{RESULTS}

A total of 136 cases were included in this study with histopathology reports of thoracic masses. Out of 136 patients, 121 were males and 15 were females. In our study, microscopic diagnosis showed that the highest number of cases belonged to the group of squamous cell carcinoma 35 . The other cases were adenocarcinoma 34 , small cell carcinoma 24 , carcinoid tumor 8 , mixed small and large cell carcinoma 4, epidermoid carcinoma 3, large cell carcinoma 2 , leiomyosarcoma 2 , signet ring cell carcinoma 1 , melanoma 1 , plasmacytoma 1 , tuberculosis 3 , schistosomiasis 1 , hydatid cyst 1 case, and nonspecific inflammation 12. The locations of lung lesions included in this study are presented on Table 1.

The squamous cell carcinoma (about 35 cases), were presented microscopically by atypical cells of different grades. The presented cells showed wide eosinophilic cytoplasm, polychromatic, with some ink spot-like nuclei, big nucleoli, and different levels of mitotic activity. The cells are forming solid nests of different size. In low grade, squamous cells carcinomas were found single or clustered, with keratinization, and highly differentiated, probably due to the presence of keratin pearls [See Figure 1].

In adenocarcinoma (34), the atypical cells are most often with different amount of eosinophilic partly vacuolated cytoplasm and polychromatic nuclei with prominent to big nucleoli and different levels of mitotic activity. The atypical cells are forming small glands of different size,

Table 1: Site distribution of the neoplastic lung lesions

\begin{tabular}{lccccc}
\hline Site & $\begin{array}{l}\text { Squamous } \\
\text { carcinoma }\end{array}$ & Adenocarcinoma & $\begin{array}{c}\text { Small cell } \\
\text { carcinoma }\end{array}$ & $\begin{array}{c}\text { Other } \\
\text { neoplastic }\end{array}$ & Total \\
\hline Right & 14 & 19 & 14 & 9 & 56 \\
Left & 21 & 13 & 10 & 15 & 59 \\
Mediastinal & - & - & - & 1 & 1 \\
Bilateral & - & 2 & - & - & 2 \\
Total & 35 & 34 & 24 & 25 & 118 \\
\hline
\end{tabular}

Distribution of the neoplastic lesions according to site 
papillary, and cribriform structures, and in low differentiated adenocarcinomas, the cells are forming mostly solid nests of different size [Figure 2a and b].

Undifferentiated small cell carcinoma is proliferation of relatively small cells with scanty cytoplasm and hyperchromatic nuclei with rough chromatin structure, usually high mitotic activity and nuclear molding. Very often in this type of tumor are found irregular different size fields of coagulation necrosis [Figure 3a and b].

In high-grade carcinomas, immunochemistry for CK 5, CK 7 , thyroid transcription factor 1 , and CK 20 for differentiation between adenocarcinoma and squamous cell carcinoma were used [Figure 4].

In cases of small cell carcinoma, immunochemistry for chromogranin and synaptophysin might be positive [Figures 5 and 6].

Sex distribution of lung malignancies is presented in Table 2.

Smoking habits and lung malignancies' relations are presented in Table 3.

Table 2: Sex distribution of lung malignancies

\begin{tabular}{lccc}
\hline Diagnosis/sex & Male & Female & Total \\
\hline Adenocarcinoma & 27 & 7 & 34 \\
Small cell carcinoma & 24 & - & 24 \\
Carcinoid tumor & 7 & 1 & 8 \\
Squamous cell carcinoma & 1 & 34 & 35 \\
Epidermoid carcinoma & 2 & 1 & 3 \\
Lymphoma & - & 1 & 1 \\
Leiomyosarcoma & 1 & 1 & 2 \\
Signet ring carcinoma & - & 1 & 1 \\
Mesothelioma & 1 & - & 1 \\
& 63 & 46 & 109 \\
\hline
\end{tabular}

CA - Cancer

Table 3: Lung tumors smoking relations

\begin{tabular}{lcc}
\hline Diagnosis/habit & Smokers & Not smokers \\
\hline Adenocarcinoma & 20 & 14 \\
Small cell carcinoma & 16 & 8 \\
Carcinoid & 3 & 5 \\
Squamous cell carcinoma & 25 & 10 \\
Epidermoid CA & 2 & 1 \\
Lymphoma & - & 1 \\
Leiomyosarcoma & - & 2 \\
Plasmacytoma & - & 1 \\
Melanoma & 1 & - \\
Signet ring carcinoma & - & 1 \\
Mesothelioma & 1 & - \\
Total & 71 & 40 \\
\hline CA - Cancer & &
\end{tabular}

The findings of this study provide additional evidence for relationship between smoking and histologic types of lung cancer; the association was stronger with squamous cell carcinoma and small cell carcinoma than with adenocarcinoma and carcinoid tumors.

\section{DISCUSSION}

Tru-cut biopsy is an accurate and safe method for evaluation of neoplastic proliferation in different locations including pulmonary lesions. ${ }^{[2-410]}$ With careful handling, this type of obtaining tissue for microscopic study is very effective in diagnosis of cancer of prostate, liver, bone marrow, joints, bones, lymph nodes, and kidneys, however, it is less effective in differentiation between malignant follicular proliferations of thyroid glands. ${ }^{[5]}$ It

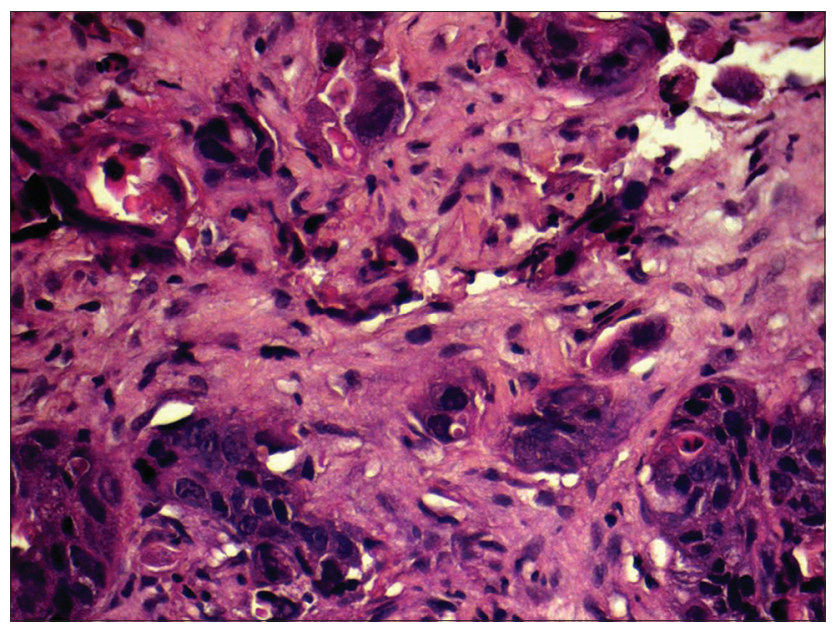

Figure 1: Infiltrating nests of tumor cells separated by desmoplastic stroma

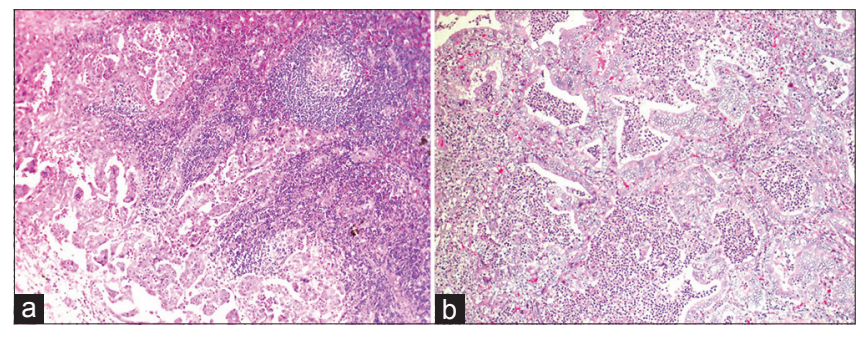

Figure 2: (a) infiltrating borders. (b) vacuolated cytoplasm and polychromatic nuclei with prominent to big nucleoli and different levels of mitotic activity

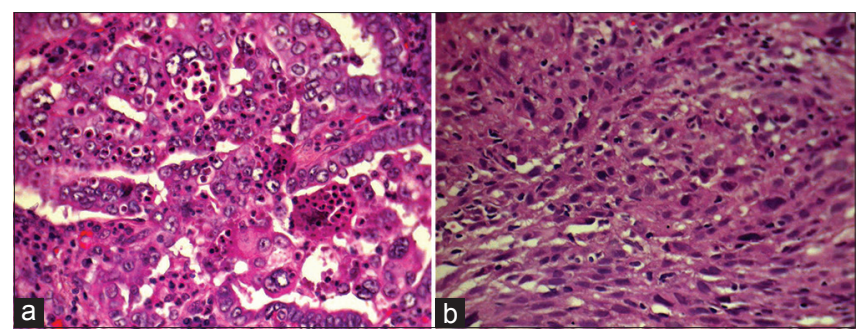

Figure 3: (a) hyperchromatic nuclei with rough chromatin structure. (b) the cells arranged in sheets, hyperchromatic nuclei 


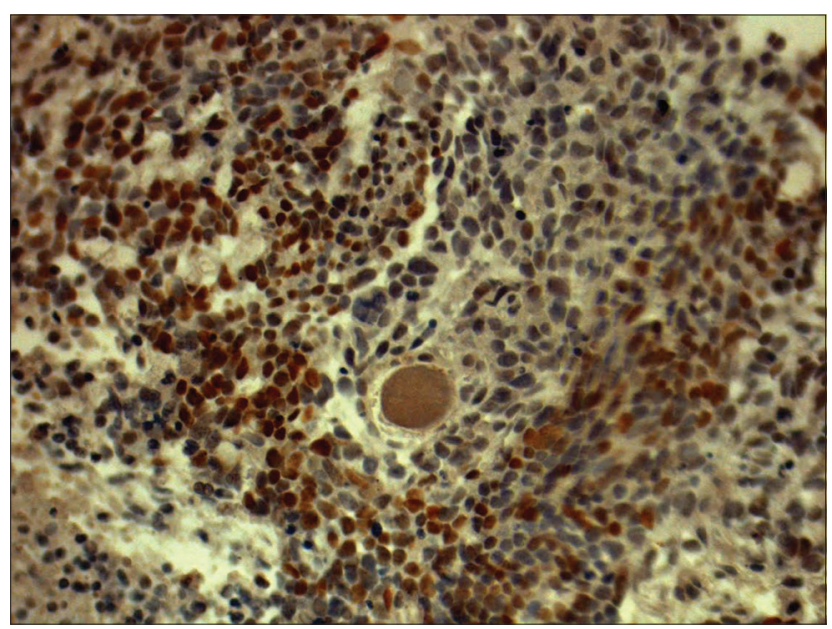

Figure 4: The tumor cells show expression of the thyroid transcription factor 1 stain

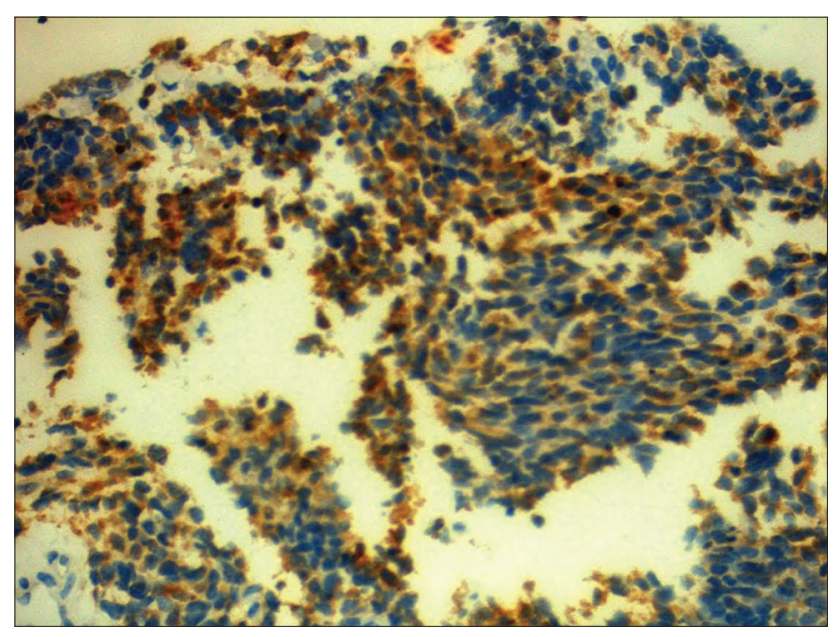

Figure 5: Chromogranin is marker stain in neuroendocrine tumor

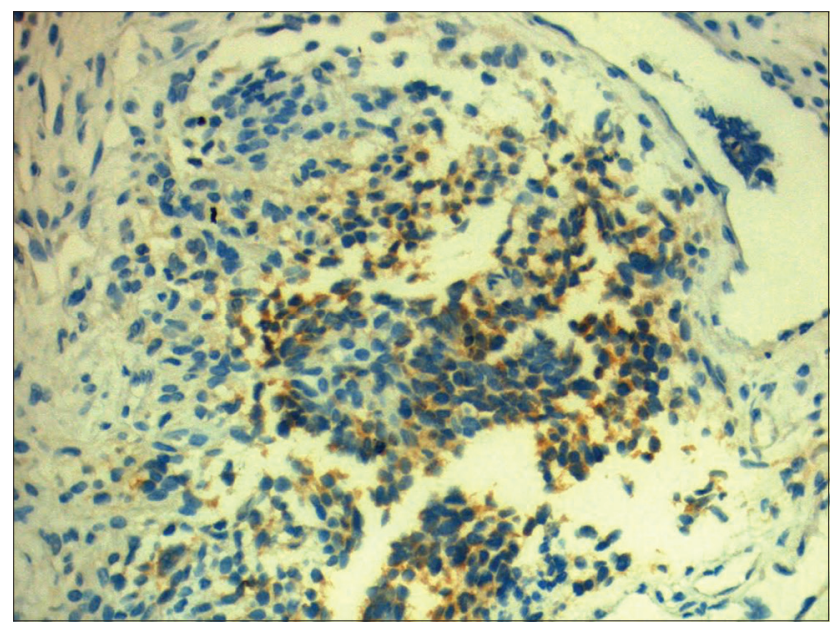

Figure 6: Positive immunostaining for synaptophysin

enables classification of malignant lesions in most of the cases. In our present study, 136 biopsies from lung mass lesions were evaluated over a period of 3 years; all cases showed adequate tissue samples (the inadequate samples are excluded from this study). The peak age of incidence was 65-67 years. Of these cases, 19 were benign and 117 were malignant, microscopically evaluated. The reason may be due to increased incidence of malignancy in this age group as Tru-cut biopsy was mainly used for diagnosis of lesions suspicious for cancer. Lung tumors were located more on the right side than on the left. Among the patients, $95.68 \%$ were heavy smokers. The malignant cases formed largest group including carcinoma, neuroendocrine tumors, and sarcoma. Among all 136 cases of malignant lung tumors, the most common $(n=35,25.17 \%)$ was squamous cell carcinoma followed by adenocarcinoma $23.02 \%$ and small cell carcinoma $17.26 \%$. The incidence of squamous cell carcinoma was reported to be insignificantly higher than that of adenocarcinoma. Maximum cases of lung malignancy were primary while only 3 cases were presented as 2 cases of metastatic adenocarcinoma of breast and 1 case of metastatic melanoma. Asymptomatic pneumothorax was the most common complication. The overall rate of complications was $19.42 \%$. Participants of the current experienced mild hemorrhage in 12 cases, mild pneumothorax in 14 cases, and air embolism in 1 case. All patients were managed conservatively, however, the patient with air embolism was admitted to the Intensive Care Unit (ICU). In this study, CT-guided cut biopsy showed almost perfect agreement with radiological images and clinical situation. Hence, CT-guided biopsy diagnosis alone can be used with confidence to select treatment modalities and to avoid unnecessary surgeries of patients with primary or metastatic lung malignancies or small cell lung carcinoma and to avoid unnecessary thoracotomy for diagnostic purposes. For microscopic diagnosis, Tru-cut biopsy is preferred approach to fine needle cytology because the tissue obtained in most of the cases is enough for immunochemistry and diagnosis of different types of lung carcinoma with differentiation between primary and metastatic pulmonary malignancies.

\section{CONCLUSION}

CT-guided Tru-cut biopsy is a simple, safe, and reliable procedure with high diagnostic accuracy for the diagnosis and subtyping of lung cancer. It is also useful for the diagnosis of tuberculous lung lesions. Immediate assessment specimen adequacy, inadequate/nonmalignant smears in particular, needs clinical correlation, close follow-up, and re-biopsy, if necessary. The definitive result of malignancy is a base for correct decision for the patient's treatment after careful clinical correlation with performance state, radiology findings, and complete serological investigations.

\section{Acknowledgment}

This study was supported by MCC, Radiology, and Histopathology Departments. We also thank our colleagues 
from Misurata Research and Skills Center who provided insights and expertise that greatly assisted the authors during the course of this research.

\section{Financial support and sponsorship}

This study was financially supported by Misurata Cancer

\section{Center.}

\section{Conflicts of interest}

There are no conflicts of interest.

\section{REFERENCES}

1. Types of biopsies used to look for cancer. The American Cancer Society. 2015. Available from: URL:https://www.cancer.org/treatment/ understanding-your-diagnosis/tests/testing-biopsy-and-cytologyspecimens-for-cancer/biopsy-types.html. [Last accessed on 2017 Apr 27].

2. Enzinger FM, Weiss SW. Soft Tissue Tumors. $3^{\text {rd }}$ ed. New York: USA: Mosby; 1995.
3. Mondal S, Nag D, Das R, Palash M, Pranab B, Manish O. Computed tomogram guided fine-needle aspiration cytology of lung mass with histological correlation: A study in Eastern India.(Mini Symposium FNAC versus Core Biopsy: Original Article)(Report). S Asian J Cancer 2013;2:14.

4. Manhire A, Charig M, Clelland C, Gleeson F, Miller R, Moss H, et al. Guidelines for radiologically guided lung biopsy. Thora $\times 2003 ; 58: 920-36$.

5. Rosai J. Surgical Pathology. $10^{\text {th }}$ ed. Edinburgh, New York: Elsevier Canada; 2011.

6. Tan KB, Thamboo TP, Wang SC, Nilsson B, Rajwanshi A, Salto-Tellez M, et al. Audit of transthoracic fine needle aspiration of the lung: Cytological subclassification of bronchogenic carcinomas and diagnosis of tuberculosis. Singapore Med J 2002;43:570-5.

7. Westcott JL. Needle biopsy of the chest. In: Tavares J, Ferrucci J, editors. Imaging Diagnosis Intervention. $2^{\text {nd }} e d$. Philadelphia: Lippincott; 1993.

8. Charig MJ, Stutley JE, Padley SP, Hansell DM. The value of negative needle biopsy in suspected operable lung cancer. Clin Radiol 1991;44:147-9.

9. Küçük CU, YilmazA, YilmazA,Akkaya E. Computed tomography-guided transthoracic fine-needle aspiration in diagnosis of lung cancer: A comparison of single-pass needle and multiple-pass coaxial needle systems and the value of immediate cytological assessment. Respirology 2004;9:392-6.

10. Cham MD, Lane ME, Henschke CI, Yankelevitz DF. Lung biopsy: Special techniques. Semin Respir Crit Care Med 2008;29:335-49. 